\title{
Desempenho funcional de servidores autônomos após um programa de ginástica laboral
}

\author{
Functional performance of stand-alone servers after a gymnastics program \\ El desempeño funcional de los servidores independientes \\ después de un programa de gimnasia
}

\author{
Murilo CAMPAGNONI ${ }^{1}$ \\ Clara Angela Carlini OGLIRI ${ }^{2}$ \\ Juliana Pereira Scoss BÖLL ${ }^{3}$ \\ Dulce Mari HERBST ${ }^{4}$ \\ William Cordeiro de SOUZA ${ }^{5}$ \\ Luis Paulo Gomes MASCARENHAS ${ }^{6}$ \\ ${ }^{1}$ Especialista em Educação e Sociedade, Graduado em Educação pela Universidade do Contestado, UnC-Curitibanos, Curitibanos - SC, Brasil \\ ${ }^{2}$ Especialista em Natação. Professora do Departamento de Educação Física da Universidade do Contestado, UnC - Curitibanos/SC \\ ${ }^{3}$ Mestre em Educação. Professora da Universidade do Contestado, UnC-Curitibanos, Curitibanos - SC, Brasil \\ ${ }^{4}$ Mestre em Educação Física. Professora do Departamento de Educação Física da Universidade do Contestado, UnC - Porto União/SC \\ ${ }^{5}$ Especialista em Fisiologia do Exercício com Ênfase em Treinamento Esportivo. \\ Professor do Departamento de Educação Física da Universidade do Contestado, UnC-Porto União, Porto União - SC, Brasil \\ ${ }^{6}$ Doutor em Saúde da Criança e do Adolescente, \\ Professor do Programa de Mestrado em Desenvolvimento Comunitário, Unicentro-Irati, Irati - PR, Brasil
}

\begin{abstract}
Resumo
O presente estudo teve como objetivo verificar a melhoria no desempenho funcional de servidores autônomos, após a participação em um programa de Ginástica Laboral (GL). Esta pesquisa é de caráter quantitativo, na qual foi utilizado um questionário composto de 10 questões fechadas de múltipla escolha relacionadas à saúde do trabalhador e o ambiente ocupacional de trabalho. A GL aplicada foi do tipo preparatório e aconteceu três vezes por semana com duração de três meses. Maior parte dos funcionários exercem funções repetitivas e de alto esforço físico (encanadores e a escavação). Há um número expressivo de funcionários que exercem suas determinadas funções há mais de 20 anos. Foi evidenciado um aumento significativo $(p=0,003)$ quanto à disposição dos funcionários após o programa de GL, o mesmo ocorreu em relação à comparação do ambiente de trabalho antes e após o programa de GL ( $\mathrm{p}=0,04)$. Após a intervenção do programa de GL, foi possível verificar uma mudança significativa $(p=0,001)$ na satisfação dos servidores quanto à concentração. Quando à intensidade da dor ou do desconforto dos funcionários foi possível verificar dados significativos $(\mathrm{p}=0,01)$ antes e após GL. Foi possível notar que a GL favoreceu o desempenho das funções de todos os trabalhadores do setor técnico com uma diferença estatística entre o pré e o pós $(\mathrm{p}=0,001)$. Constatou-se que a GL é eficiente na melhoria do ambiente de trabalho, no desempenho dos funcionários, diminuindo as dores e desconforto no corpo.
\end{abstract}

Descritores: Ginástica; Saúde do Trabalhador; Transtornos Traumáticos Cumulativos.

\begin{abstract}
This study aimed to verify the improvement in functional performance of stand-alone servers, after participating in a gymnastics program (GP). This research is quantitative approach, in which we used a questionnaire consisting of 10 closed questions multiple choices related to worker health and occupational work environment. GP applied was the preparatory kind and took place three times a week lasting three months. Most employees perform repetitive tasks, high physical exertion (plumbers and excavation). There are a significant number of employees who perform their specific functions for over 20 years. A significant increase was demonstrated ( $\mathrm{p}=$ 0.003 ) and to the staff after the GP program, the same occurred with no comparison of the work environment before and after the GP program $(p=0.04)$. After the intervention of the GP program, we found a significant change $(p=0.001)$ in satisfaction of the servers as the concentration. When the intensity of pain or discomfort of employees we observed significant data $(\mathrm{p}=0.01)$ before and after GP. It observed that GP favored the functions of all workers in the technical sector with a significant difference between pre and post ( $\mathrm{p}=$ 0.001). It was found that the GP is effective in improving the working environment, employee performance, reducing the pain and discomfort in the body.
\end{abstract}

Descriptors: Gymnastics; Occupational Health; Cumulative Trauma Disorders.

\section{Resumen}

Este estudio tuvo como objetivo comprobar la mejora en el rendimiento funcional de servidores independientes, después de participar en un programa de gimnasia (GL). Esta investigación es enfoque cuantitativo, en el que se utilizó un cuestionario que consta de 10 preguntas cerradas de opción múltiple relacionadas con la salud de los trabajadores y medio ambiente de trabajo en el trabajo. GL aplicado fue el tipo de preparación y se llevó a cabo tres veces a la semana que dura tres meses. La mayoría de los empleados realizan tareas repetitivas, de alto esfuerzo físico (fontaneros y excavación). Hay un número significativo de empleados que realizan sus funciones específicas durante más de 20 años. Un aumento significativo se demostró $(p=0,003)$ y para el personal después de que el programa de GL, lo mismo ocurrió con ninguna comparación del entorno de trabajo antes y después del programa GL ( $\mathrm{p}=0,04)$. Después de la intervención del programa GL, encontramos un cambio significativo $(\mathrm{p}=0,001)$ en la satisfacción de los servidores como la concentración. Cuando la intensidad del dolor o el malestar de los empleados se observó datos significativos ( $\mathrm{p}=0,01)$ antes y después de GL. Se observó que GL favoreció las funciones de todos los trabajadores en el sector de la técnica con una diferencia significativa entre pre y post $(\mathrm{p}=0,001)$. Se encontró que la GL es eficaz para mejorar el entorno de trabajo, rendimiento de los empleados, lo que reduce el dolor y la incomodidad en el cuerpo.

Descriptores: Gimnasia; Salud Laboral; Trastornos de Traumas Acumulados. 


\section{INTRODUÇÃO}

As empresas buscam constantemente melhorar seu desempenho e alcançar bons índices na área em que estão atuando. Um dos fatores que contribuem no alcance destes índices é a produtividade do funcionário dentro do melhor tempo possível. Contudo, esta busca de resultados pode sobrecarregar o trabalhador, levando o mesmo a realizar tarefas repetitivas em busca de produtividade $^{1}$.

Dados levantados pela previdência social mostram que no ano de 2011 houve um aumento no número total de acidentes de trabalho registrados no Brasil, de 709.474 casos em 2010 para 711.164 em $2011^{2}$.

As estatísticas continuam demonstrando a necessidade de ampliação do número de auditores fiscais do Trabalho, para atuar na prevenção de acidentes, exigindo o cumprimento das Normas Regulamentadoras que tratam de Segurança e Saúde no Trabalho ${ }^{3}$.

Em alguns setores das empresas, a função dos trabalhadores remete a movimentos repetitivos, causando estresse e cansaço. Tais fatores podem gerar alguns problemas musculares, tais como os Distúrbios Osteomusculares Relacionados ao Trabalho (DORT) ${ }^{4}$.

De acordo com Martins e Duarte ${ }^{1}$ as DORTs são doenças ocupacionais resultantes de uma descompensação entre a capacidade de movimento da musculatura e a execução de movimentos repetitivos e constantes. Estas dores se caracterizam pela aparência de alguns sintomas, tais como: fadiga, cansaço e diminuição no rendimento do trabalho, problemas que podem ser compensados ou até mesmo prevenidos com a utilização da Ginástica Laboral (GL).

Os autores supracitados ainda argumentam que a GL é composta por sessões de cinco, dez ou quinze minutos de exercícios visando à prevenção das LER/DORT e a diminuição do estresse, através de exercícios de alongamento e relaxamento, ou seja, a GL utiliza exercícios buscando preparar ou compensar a estrutura osteomuscular durante todo o dia, aquecendo, relaxando.

Diante do exposto, chega-se à questão que norteia esta pesquisa: há melhora no desempenho dos servidores do SAMAE de Campos Novos - SC, após a participação em um programa de ginástica laboral? Sendo assim, a presente pesquisa objetivou verificar se após a participação em um programa de ginástica laboral ocorreu melhoria no desempenho funcional de servidores do SAMAE.

\section{MATERIAL E MÉTODO}

A população de servidores envolvida neste estudo foi de cinquenta e cinco $(n=55)$ funcionários da Empresa do Ramo de Serviço Autônomo Municipal de Água e Esgoto SAMAE que possui sua sede no município de Campos Novos-SC. A amostra deste trabalho foi do tipo censitário e teve como critério de inclusão apenas os funcionários do setor técnico do SAMAE Campos Novos - SC, compreendendo trinta $(n=30)$ participantes. Os critérios de exclusão compreenderam os funcionários que se negaram a assinar o Termo de Consentimento livre e esclarecido (nove funcionários), e os que não trabalhavam no setor técnico do SAMAE de Campos Novos (25 funcionários). A amostra final foi composta por 21 indivíduos de ambos os sexos que trabalhavam no setor técnico. Antecedendo a coleta de dados, foi encaminhado o projeto para o Comitê de Ética em Pesquisa para obtenção do parecer consubstanciado favorável à execução da pesquisa sob o numero 544640.

Para a coleta de dados foi utilizado como instrumento um questionário avaliativo inicial e um questionário avaliativo final bem como, um mapa de desconforto corporal que consistiu em um desenho do corpo humano segmentado em partes (ombros, braços, região dorsal, etc) que foram apresentados aos entrevistados para que assinalassem o local do desconforto. $^{5}$

Os questionários continham uma escala visual analógica (EVA), que auxiliou na aferição da intensidade da dor no paciente, foi um instrumento importante para verificarmos a evolução dos trabalhadores após as sessões de GL. As questões foram aplicadas aos trabalhadores a partir de dois momentos. Em um primeiro momento o questionário foi aplicado aos trabalhadores e coletado informações antes do início do programa de GL. No segundo momento foi aplicado o questionário final ao término de três meses de GL.

A GL aplicada foi preparatória em consistiu em exercícios específicos de aquecimento e alongamento dos membros superiores e inferiores para as áreas do corpo mais exigidas no trabalho dos servidores. Os exercícios ocorreram três vezes por semana, todas as segundas-feiras, quartas-feiras e sextas-feiras com o tempo de quinze minutos diário. $\mathrm{O}$ horário de execução ocorreu das $07 \mathrm{~h} 30 \mathrm{~min}$ às $07 \mathrm{~h} 45 \mathrm{~min}$. O primeiro mês foi um período de adaptação, correção dos movimentos e postura dos trabalhadores. $\mathrm{O}$ segundo mês foi acrescentado exercícios mais dinâmicos e de grupo. No terceiro e ultimo mês foram aplicados os mesmos exercícios com maior amplitude dos movimentos.

Os dados coletados foram de fonte primária. Os próprios funcionários forneceram as informações e estas foram tabuladas em Microsoft Excel ${ }^{\circledR}$, analisadas e apresentadas em forma de gráficos, seguidas de uma análise descritiva para uma melhor compreensão dos resultados, e recorreu-se ao teste do Qui-quadrado, com um nível de significância de p>0,05 para verificar a associação entre as frequências percentuais nos resultados obtidos antes do início do programa e ao término das atividades de GL. 


\section{RESULTADOS E DISCUSSÃO}

O dados apresentados no Gráfico 1 demonstram que a função de auxiliar de operações se sobrepõem aos demais setores de trabalho dentro da empresa.

Gráfico 1. Proporção das funções desempenhadas pelos Funcionários Técnicos

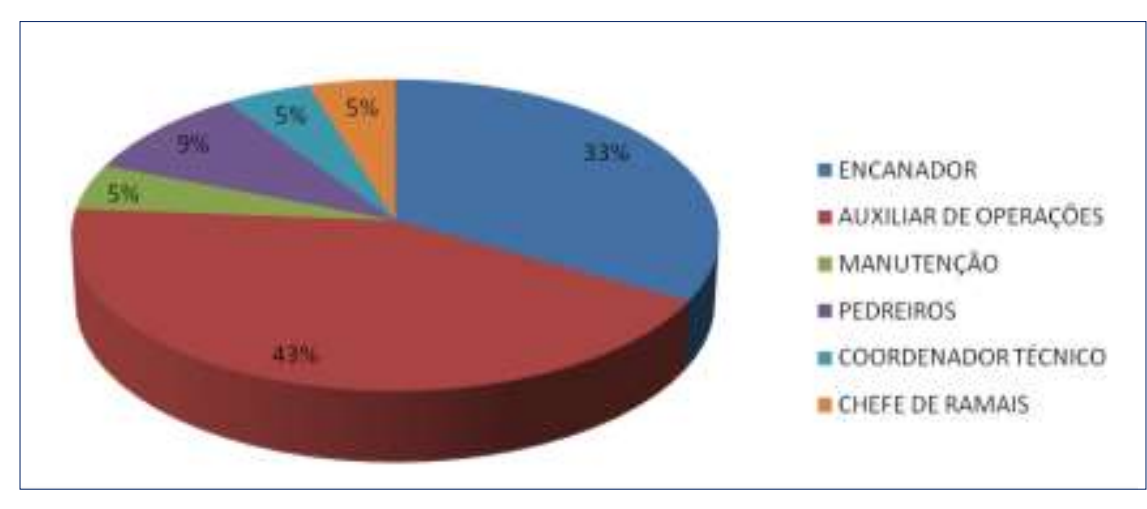

Baseado nos resultados do Gráfico 1 se nota que a maior parte dos funcionários exerce funções repetitivas e de alto esforço físico, pois as funções mais executadas pelos auxiliares são as que envolvem atividades como encanador e escavação. Em decorrência da função que exercem é inevitável que apresentem dores e cansaço, ao longo do dia.

Oliveira $^{7}$ destaca que os profissionais que exercem funções repetitivas necessitam de atividades físicas de alongamento e relaxamento para manterem-se ativos e bem dispostos. Esse mesmo autor afirma que é muito importante conscientizar as pessoas dos benefícios de um programa de GL e, que este seja orientado e adequado à prevenção de doenças osteomusculares, através de alongamentos.

O Gráfico 2 apresenta o histórico dos funcionários dentro da empresa (tempo de prestação de serviço).

Gráfico 2. Histórico do funcionário (Tempo de Prestação de Serviços)

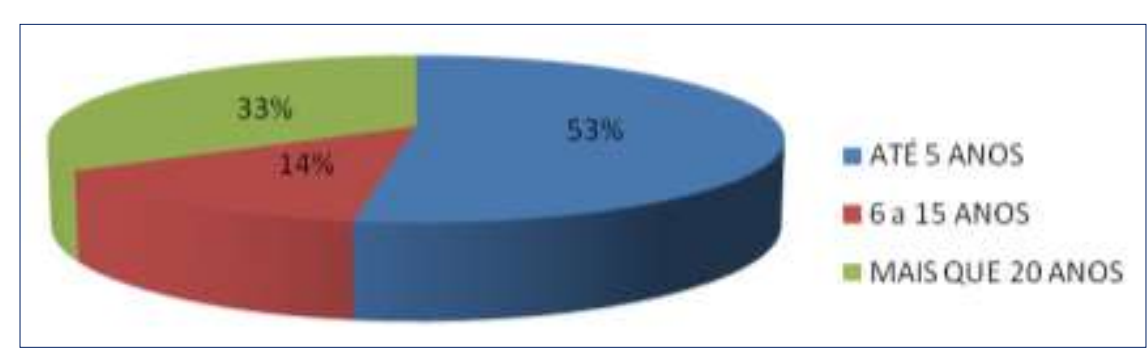

A análise dos dados apresentados no Gráfico 2 revela que a empresa possui um número expressivo de funcionários que exercem suas determinadas funções há mais de 20 anos, em contrapartida mais da metade dos funcionários técnicos trabalham na empresa até 5 anos o que mostra que a equipe de servidores está sendo renovada e que os funcionários sentem-se tranquilos em permanecer na empresa por mais tempo. Segundo relatos dos servidores e do departamento de Recursos Humanos, a cada 2 anos a empresa abre concurso para suprir a necessidade no preenchimento das vagas excedentes.

No entanto, as empresas não devem esquecer que exercem uma responsabilidade ímpar na sociedade. Para
$\mathrm{Maciel}^{8}$ as empresas não devem se limitar apenas ao papel de fontes geradoras de emprego e renda, porém devem levar o servidor a interagir com o meio e transformá-lo. Pelo exposto, pode se notar que o estilo de vida que dos funcionários levam em suas atividades laborais influenciaram diretamente no desempenho da empresa. O programa de GL pode aumentar a disposição destes funcionários que atuam há vários anos no departamento e mantém a disposição dos demais que atuam há poucos anos dentro da organização. O Gráfico 3 demostra a comparação quanto a disposição dos funcionários (antes e depois) do programa de GL.

Gráfico 3. Comparação quanto a disposição dos funcionários (antes e depois) do programa de 3 meses de GL

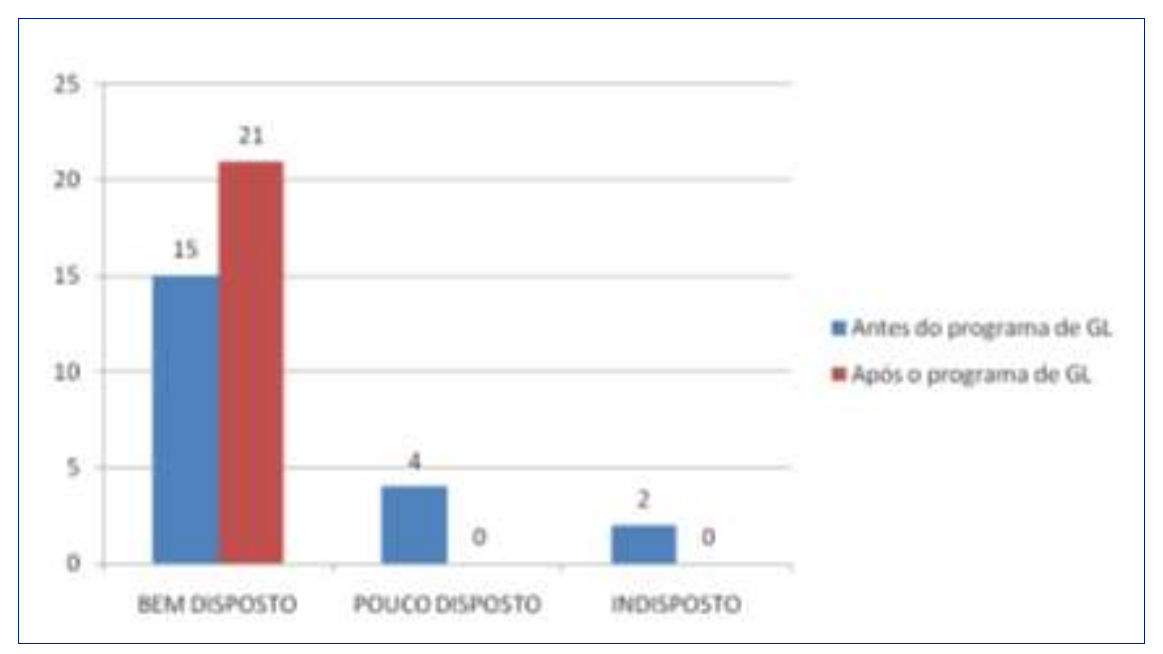

O Gráfico 3 evidencia um significativo $(\mathrm{p}=0,003)$ aumento quanto à disposição dos funcionários após o programa de GL. O questionário inicial indicava que 15 indivíduos se sentiam bem dispostos ao iniciar suas tarefas diárias e após três meses de GL passaram para 21 o número de trabalhadores bem dispostos em sua função, o que vai ao encontro com relatos dos funcionários sobre sua disposição no período da manhã, após as atividades propostas pelo programa de GL. Sendo assim, a Ginástica Laboral Pós (GLP) proporcionou mais disposição aos trabalhadores em relação ao período em que não a praticavam.

Como comenta Polito e Bergamaschi ${ }^{9}$ a GLP prepara os indivíduos para suas necessidades laborais as quais podem ser de velocidade, força, resistência, aperfeiçoando as coordenações e sinergias, auxiliando para que os trabalhadores iniciem suas atividades com maior disposição. O Gráfico 4 abaixo mostra a comparação do Ambiente de Trabalho (relações interpessoais) dos Funcionários após 3 meses de GL.

O Gráfico 4 apresenta a comparação do ambiente de trabalho antes e após o programa de três meses de GL, evidenciando resultados relevantes e significativos $(\mathrm{p}=0,04)$ para o quadro de servidores. O questionário inicial mostrou que 2 funcionários achavam ruim seu ambiente de trabalho, e após o programa de GL nenhum deles denominou seu ambiente de trabalho ruim.

$\mathrm{Na}$ aplicação do primeiro questionário, 19 pessoas achavam seu ambiente de trabalho bom e após o 
programa de GL desenvolvido na empresa apenas 10 pessoas consideraram ser bom o espaço em que estão inseridas para desenvolver suas atividades laborais. Ainda com relação ao Gráfico 4, é possível afirmar que no início do programa nenhum funcionário denominou seu local de trabalho como ótimo, e após os três meses de GL houve um aumento considerável de funcionários que apontaram-no como ótimo.

Gráfico 4. Comparação do Ambiente de Trabalho (relações interpessoais) dos Funcionários após 3 meses de GL

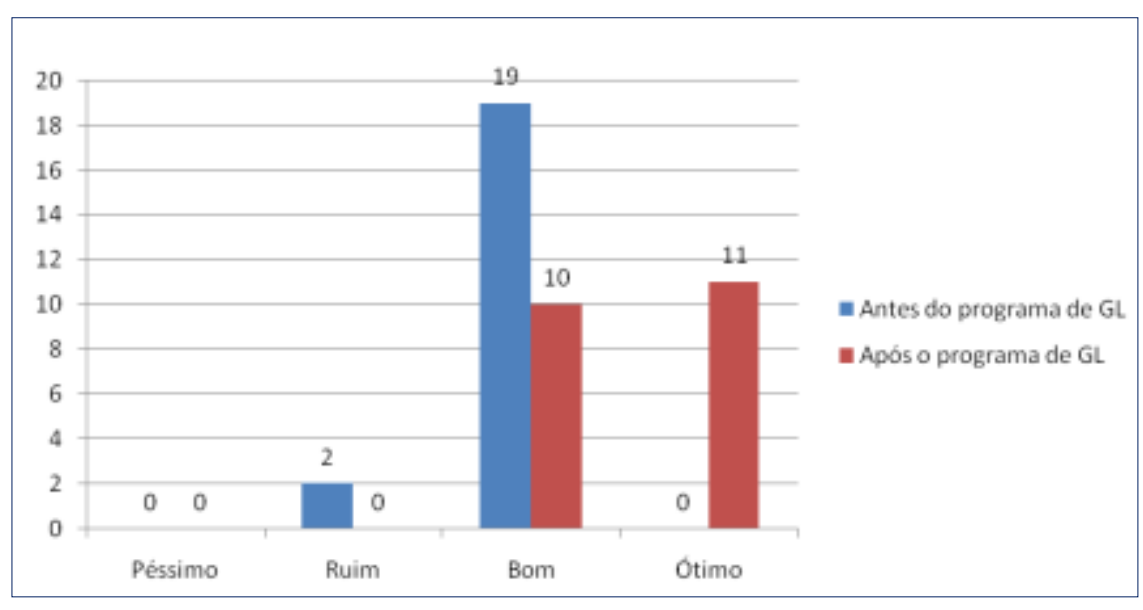

Foram 11 os funcionários que apontaram como ótimo o ambiente ocupacional. A partir desta representação verificou-se uma migração dos servidores que responderam ao questionário inicial quanto à satisfação no ambiente de trabalho e as relações interpessoais. Os indivíduos que consideravam o ambiente bom passaram a considerá-lo ótimo. Neste sentido com a participação dos funcionários no programa de GL o ambiente de trabalho melhorou. O resultado revelou trabalhadores mais satisfeitos em seu ambiente ocupacional. O Gráfico 5 apresenta a comparação da concentração dos trabalhadores (antes e após) 3 meses de Ginástica Laboral.

Gráfico 5. Comparação da concentração dos trabalhadores (antes e após) 3 meses de GL

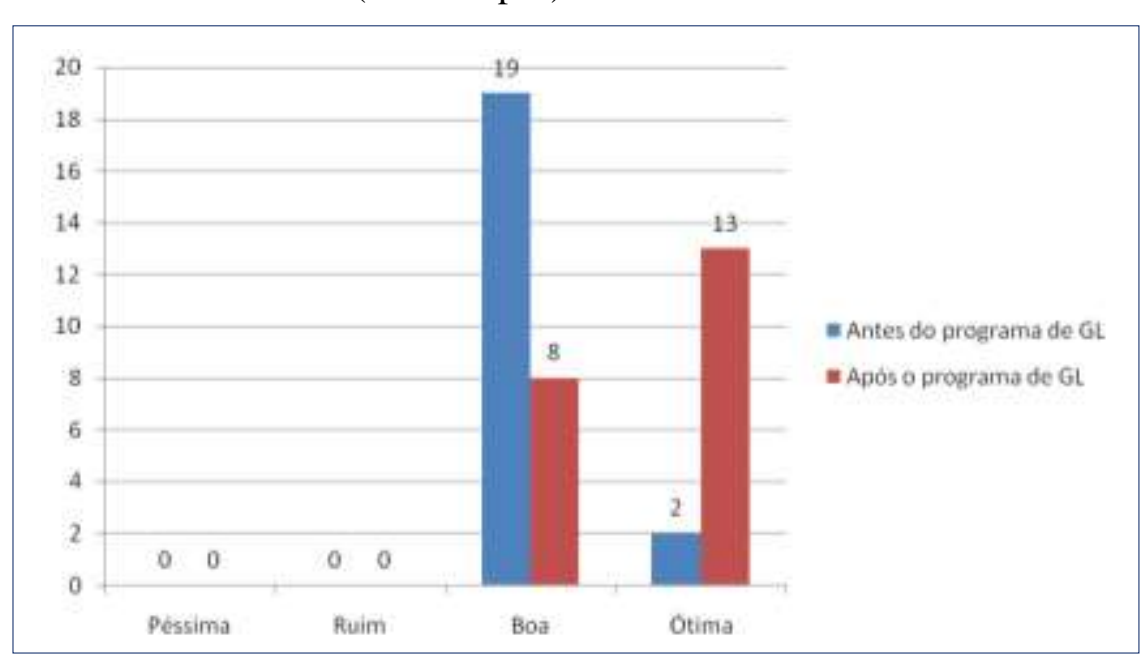

Com base nos resultados apresentados no Gráfico 5 foi possível observar que 19 trabalhadores julgaram boa a sua concentração, no questionário final após o programa, diminui para 8 profissionais os quais responderam boa sua concentração pela manhã, o que nota uma queda de 11 indivíduos. Em contrapartida no início do programa 2 pessoas denominavam sua concentração ótima e após o programa de GL 13 pessoas sentiam sua concentração ótima, mostrando um aumento significativo na concentração dos servidores.

O Gráfico 5 representou quanto ao nível de concentração dos servidores antes do programa GL que: 19 dos funcionários consideraram ser boa sua capacidade de concentração; 2 servidores julgaram ser ótima e nenhum indivíduo respondeu que seu nível de concentração é péssimo ou ruim. Conforme mostra o gráfico acima, após três meses de aplicação do programa de GL, os servidores demonstraram satisfação, que foi revelada pelo gráfico em análise. Confirma-se então uma mudança significativa $(p=0,001)$ na satisfação dos servidores quanto à concentração após o programa de atividades. Segundo Mendes e Leite ${ }^{10}$ a GL irá despertar os funcionários para desempenhar melhor suas funções, prevenindo lesões ocupacionais e deixando-os mais concentrados e com menos risco de erros no trabalho. $\mathrm{O}$ Gráfico 6 demostra a incidência da intensidade de dores (antes e após) 3 meses de GL.

Gráfico 6. Incidência da intensidade de dores (antes e após) 3 meses de GL

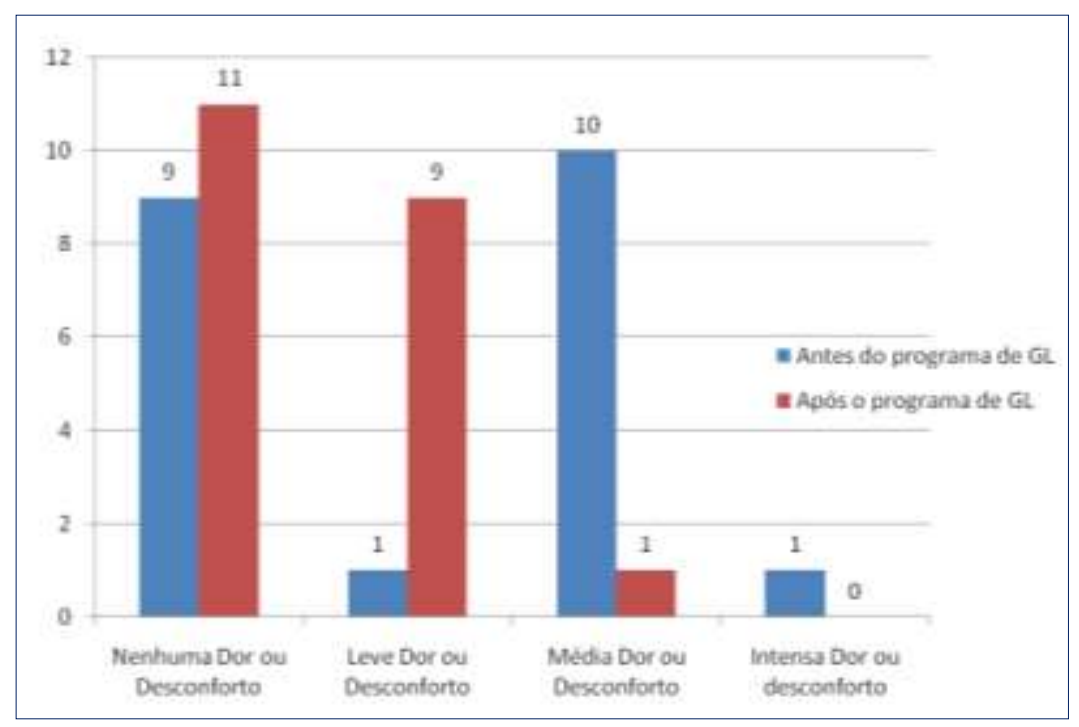

O Gráfico 6 revela dados significativos $(\mathrm{p}=0,01)$, antes e após o programa de GL, referentes à intensidade da dor ou do desconforto dos funcionários. No questionário inicial, 9 pessoas não sentiam nenhuma dor ou desconforto e após o programa de GL 11 servidores responderam que não sentem mais nenhuma dor ou desconforto, evidenciando uma significativa contribuição do programa de GL.

No início do programa apenas um indivíduo sentia dor leve e/ou desconforto. Após o programa de ginástica aumentou para 9 o número de trabalhadores com dor leve e desconforto, porém no primeiro questionário 10 servidores sentiam dor média dor ou desconforto e passou para 1 indivíduo com dor média e desconforto, nos mostrando que a ginástica laboral diminuiu a intensidade de dores nos funcionários e até mesmo sanando as dores daqueles que sentiam um dor mais leve. Evidencia-se o número de trabalhadores que apresentaram dor ou desconforto de intensidade média e passaram a apresentar dores ou desconforto leve após o programa de GL. O que demonstra que a aplicabilidade da GL é um benefício para os servidores. Polito e 
Bergamaschi ${ }^{9}$ postulam que este tipo de atividade física procura prevenir lesões e distúrbios, buscando a saúde musculoesquelética e a diminuição do estresse. O Gráfico 7 mostra como os trabalhadores se sentiam em relação ao seu trabalho antes do início do programa de GL.

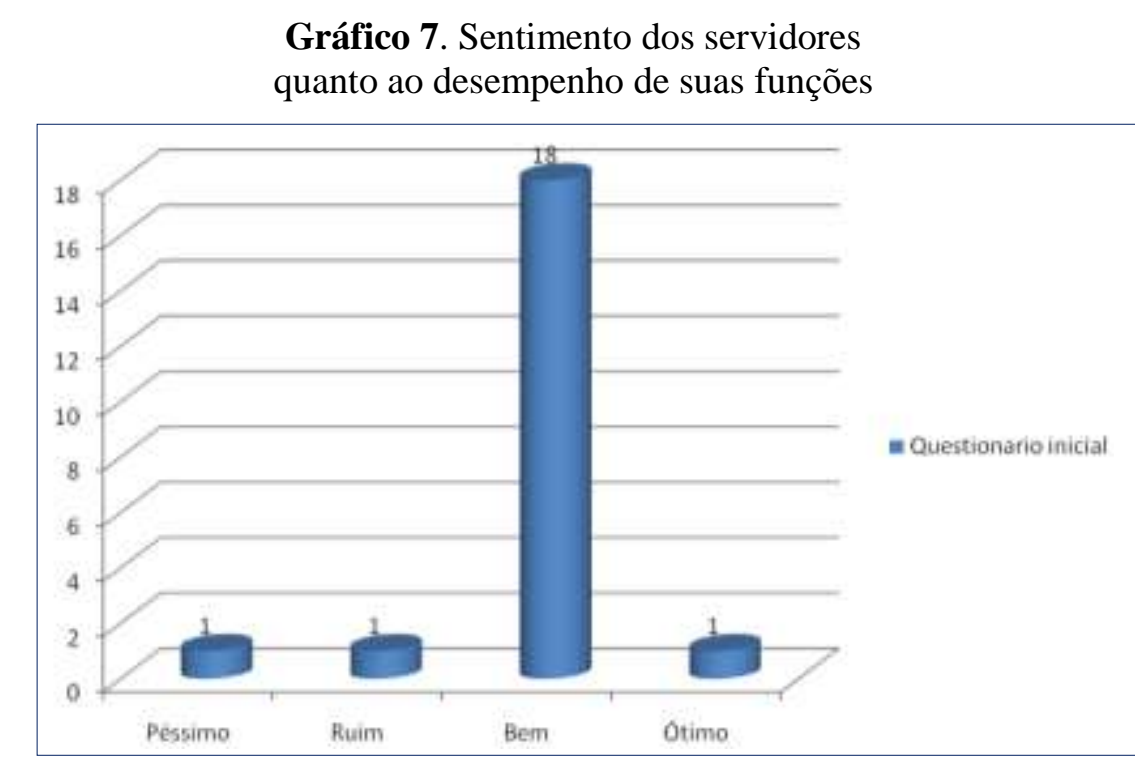

Com base nos resultados do gráfico 7 observa-se que apenas 1 funcionário se sentia péssimo quanto ao seu desempenho no trabalho; 1 funcionário se sentia ruim quanto ao seu desempenho e; 1 trabalhador se sentia ótimo quanto ao se desempenho no trabalho.

Segundo Ranney ${ }^{11}$ os fatores que afetam as atividades dos trabalhadores são os períodos prolongados de trabalho, ausência de pausas, não rotatividade de tarefas e fatores psicológicos, tais como o estresse, pressão pela produção e o relacionamento entre chefias e funcionários.

O número maior foi de 18 servidores os quais responderam no questionário inicial se sentirem bem quanto ao seu desempenho no trabalho. Conforme os dados apresentados e de relatos dos próprios servidores a maior parte dos funcionários se sentiam bem em relação ao desempenho de suas determinadas funções.

Os gestores da empresa tinham como uma de suas principais metas o aumento da produtividade, a melhora do ambiente ocupacional e que a GL de qualquer forma ajudasse na melhoria do desempenho das funções de cada indivíduo dentro da empresa o que esta bem representada no Gráfico 8.

Os dados apresentados no Gráfico 8 mostram que 2 funcionários melhoraram um pouco o desempenho das suas funções; 8 servidores melhoraram bastante $\mathrm{o}$ desempenho de seu trabalho e; 11 trabalhadores melhoraram muito o desempenho de suas funções

Com base nos resultados do Gráfico $8 \mathrm{em}$ comparação ao Gráfico 7 foi possível notar que a GL favoreceu o desempenho das funções de todos os trabalhadores do setor técnico com um diferença estatística entre o pré e o pós $(\mathrm{p}=0,001)$. Em nenhum caso a GL não melhorou em nada a condição laboral destes funcionários.
Gráfico 8. Desempenho das funções dos servidores após o programa de 3 meses de GL

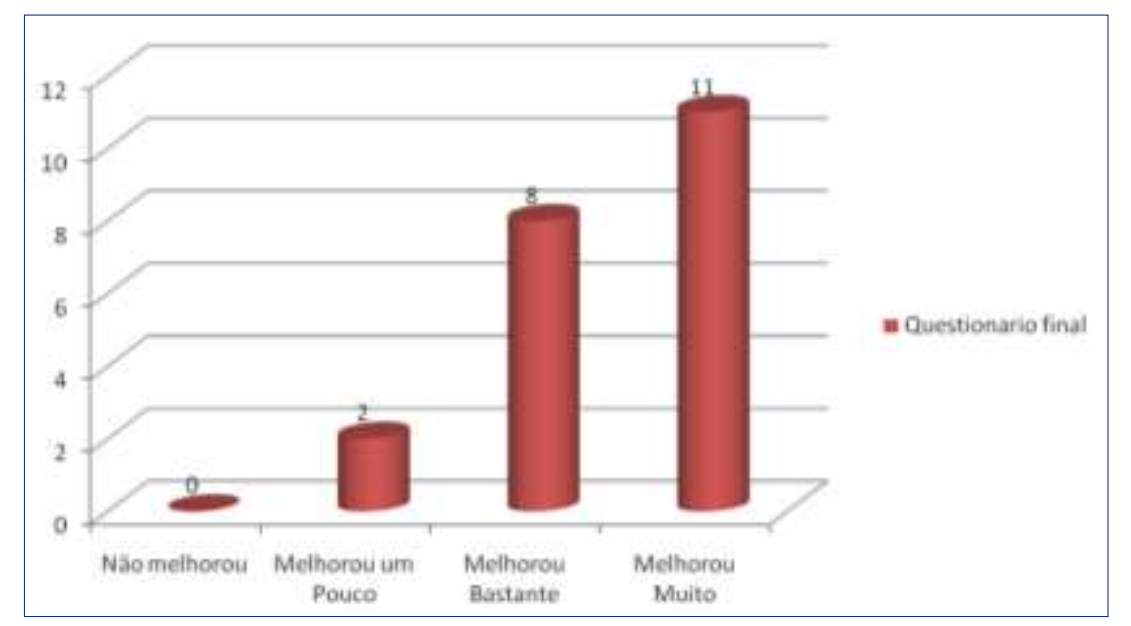

\section{CONCLUSÃO}

Os resultados apresentados nos três meses de GL mostraram que a aplicação do programa proporcionou uma diminuição nas dores musculares dos servidores do setor técnico, e percebeu-se que a intensidade de seu desconforto também diminuiu. Foi observado que, após o programa de GL, houve uma melhora considerável no desempenho funcional dos servidores. Além disso, cabe ressaltar que após o programa houve uma evolução nas relações interpessoais.

Foram observados os servidores técnicos, de forma a diferenciar o atendimento de outros programas, pois a maioria dos trabalhos direcionados a esta área são voltados ao setor administrativo. Os números apresentados no decorrer do estudo evidenciaram que se a pesquisa tivesse sido aplicada por mais tempo e fossem incluídas no programa a Ginástica Laboral Compensatória (GLC) e a Ginástica Laboral de Relaxamento (GLR) o resultado seria mais expressivo, o que abre espaço para posteriores estudos nesta área.

\section{REFERÊNCIAS}

1. Martins C, Duarte MFS. Efeitos da Ginástica Laboral em servidores da Reitoria da UFSC. Rev Bras Ciê e Mov. 2000;5(4):7-13.

2. Previdência Social. Anuário Estatístico de Acidentes de Trabalho de 2011. Disponível em: <http://www.tst.jus.br/ web/ trabalhoseguro/dadosnacionais $>$. Acesso em 15. Set. 2014.

3. Legislação Comentada. Normas Regulamentadoras de Segurança e Saúde do Trabalho. Disponível em: $<$ https://moodle.ufsc.br/pluginfile.php/748669/mod_r esource/content/1/NRs_Comentadas.pdf $>$ Acesso em 01.Jul. 2014.

4. Vasconcelos FD. Atuação do Ministério do Trabalho na fiscalização das condições de segurança e saúde dos trabalhadores, Brasil, 1996-2012. Rev Bras Saúde Ocup. 2014;39(129):86-100.

5. Corlett EN, Manenica I. The effects and measurement of working postures. Applied Ergonomics. 1980;11(1):7-16. 
6. Oliveira JRG. A prática da ginástica laboral. $3^{\mathrm{a} e d}$. Rio de Janeiro: Sprint; 2006.

7. Maciel MG. Ginástica Laboral: instrumento de produtividade e saúde nas empresas. Rio de Janeiro: Shiepe; 2008.

8. Polito E, Bergamaschi EC. Ginástica Laboral: teoria e prática. $2^{\circ}$ Ed. Rio de Janeiro: Sprint; 2003.

9. Mendes RA, Leite N. Ginástica Laboral. Princípios e aplicações práticas. $2^{\circ}$ ed. São Paulo: Editora Manole; 2008.

10. Ranney, D. Distúrbios Osteomusculares Crônicos Relacionados ao Trabalho. São Paulo: Roca; 2000.

\section{CONFLITO DE INTERESSES}

Os autores declaram não haver conflitos de interesse.

\section{AUTOR PARA CORRESPONDÊNCIA}

Murilo Campagnoni

murilo_campagnoni@hotmail.com

Submetido em 02/07/2016 Aceito em 09/08/2016 